\title{
A COMPACT MICROSTRIP ANTENNA BASED ON H-FRACTAL GEOMETRY FOR MULTI- BAND OPERATION
}

\author{
*Zainab S. Muqdad ${ }^{1}$
}

Taha A. Elwi ${ }^{2}$

\author{
Zaid A. Abdul Hassain'1
}

1) Electrical Engineering Department, College of Engineering, Mustansiriyah University, Baghdad, Iraq

2) Communication Engineering Department/ College of Engineering/ Al-Mammon University, Baghdad, Iraq

\begin{abstract}
This paper presents a compact, tri-bands, rectangular patch antenna based on $\mathrm{H}$-Tree fractal slots structure for modern wireless communication systems has been introduced. The antenna structure consists of a $70.70 \times 56 \mathrm{~mm}^{2}$ rectangular patch printed on $173 \times 173 \times 1.6 \mathrm{~mm}^{3}$ FR4 substrate. H-Tree slots fractal geometry with the defective ground plane on the other side to enhance gain and bandwidth. The suggested antenna is fed by a $50 \Omega$ microstrip line. The antenna shows three resonance frequencies: $0.784,1.158$, and $1.772 \mathrm{GHz}$. The suggested antenna offers a total size reduction of about $75 \%$. The designed antenna possesses fractional bandwidths of $3.976 \%, 7 \%$, and $2.7866 \%$ for the first, second and third resonances, respectively. Finally, the proposed antenna is a candidate for Global System for Mobile communications (GSM).
\end{abstract}

Keyword: H-Tree Fractal Slots, microstrip patch antenna, multi-band, miniaturization, wireless communication, GSM.

\section{Introduction}

Fractal geometry is defined as broken and irregular fragments that were presented by Benoit B Mandelbrot [1] to depict complicated shapes that possess self-similarity in their geometry structures and repeating themselves on different scales. In last decay, there is an increasing demand for Miniaturized reconfigurable antennas with multifunctional capabilities which have the ability to change their characteristics dynamically without affecting their size which enhances the performance of cognitive radio systems, broadband services, and wireless communications. The reconfigurable antenna has been distinguished by the capability of modifying its properties like; radiation patterns, bandwidths, frequencies, and polarization to adapt to the conditions of an environment in a way that can be controlled and reversible [2]. A broad variety of applications that uses fractal geometries have been found in a wide range of scientific and engineering applications. one of these fields Fractal electrodynamics [3], in which a new category of radiation, propagation, and scattering problems are investigated by using electromagnetic theory with fractal geometry. some of the most fractal electrodynamics research areas are antenna theory and design. which afford a boom to antenna uses in the microwave, RFID telecom, wireless, and others industry were small sizes, high performance, multiple frequencies, and important drives [4]. Numerous fractal antennas have been studied and designed, some of which

*Corresponding Author: zsalam370@gmail.com 
are: line shapes as Koch dipole [5], Hilbert shapes [6-7], Minkowski shape [8] planar shapes as Sierpinski fractal [9-10], Peano fractal [11], Koch Island [12], printed Sierpinski gasket [1314], Modified Sierpinski Gasket Monopole antenna [15] and graded slots [16].

In this paper, H-tree fractal slots antenna [17] uses, whose geometry is defined, is described by means of computational results for different iterations. It was found that, as the number of iterations increases, the resonant frequencies are shifted by a scaled ratio and the bandwidth slightly decreases. Other significant results, were also obtained for the same iterations when compared with other fractal antennas. e.g., frequency reconfigurable [18] the proposed designs can be used in the GSM network.

\section{Antenna Design}

The suggested antenna structure is designed based on H-tree fractal geometry in order to realize a multi-frequency band resonance, as well as moisturized antenna size. The proposed antenna represents the $3^{\text {rd }}$ order $\mathrm{H}$-tree patch printed on an Epoxy FR4 substrate of $\varepsilon_{\mathrm{r}}=4.3$ and loss tangent $\tan \delta=0.025$. The backside of the substrate represents the conductive layer as a ground plane. A rectangular aperture is etched out in the ground plane to reduce the effects of the capacitive coupling and surface wave leakage that significantly affect the antenna bandwidth [10-19]. The total antenna size is found to be $173 \times 173 \times 1.6 \mathrm{~mm}^{3}$. Fig. 1 represents the proposed antenna with all relative dimensions listed in Table 1.

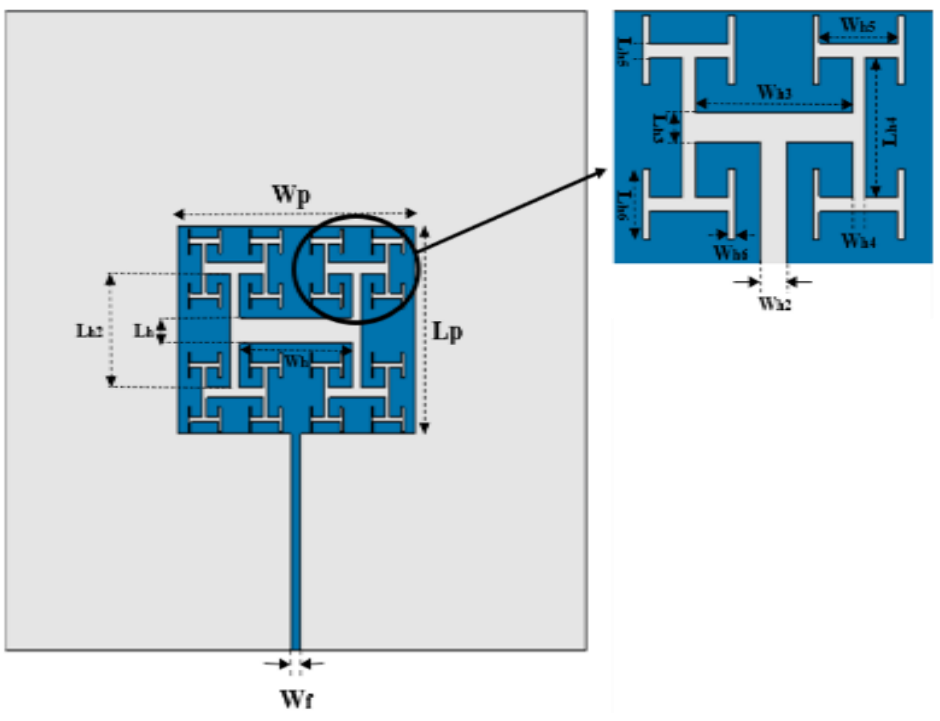

(a)

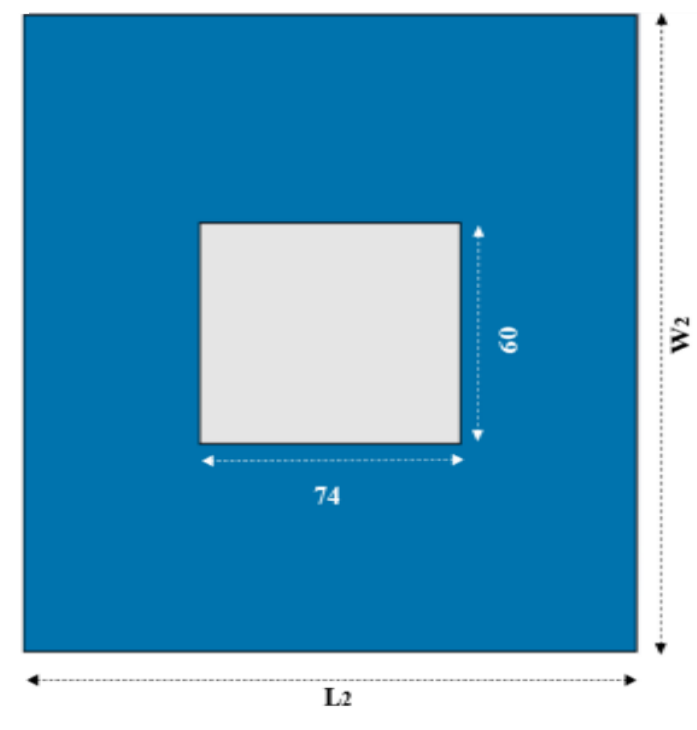

(b)

Figure 1. The proposed antenna structure geometrical details: (a) antenna patch and (b) Ground plane. Note: All dimensions are in $\mathrm{mm}$ scale. 
Table 1. Dimensions of the proposed antenna in $(\mathrm{mm})$ scale.

\begin{tabular}{cccccc}
\hline $\mathbf{W}_{\mathbf{2}}$ & $\mathbf{L}_{\mathbf{2}}$ & $\mathbf{W}_{\mathbf{p}}$ & $\mathbf{L}_{\mathbf{p}}$ & $\mathbf{W}_{\mathbf{f}}$ & $\mathbf{W}_{\mathbf{h}}$ \\
\hline 173 & 173 & 70.7 & 56 & 2.971 & 33.6 \\
$\mathrm{~L}_{\mathrm{h}}$ & $\mathrm{W}_{\mathrm{h} 2}$ & $\mathrm{~L}_{\mathrm{h} 2}$ & $\mathrm{~W}_{\mathrm{h} 3}$ & $\mathrm{~L}_{\mathrm{h} 3}$ & $\mathrm{~W}_{\mathrm{h} 4}$ \\
3.5 & 2.8 & 30.8 & 16.8 & 2.8 & 1.4 \\
$\mathrm{~L}_{\mathrm{h} 4}$ & $\mathrm{~W}_{\mathrm{h} 5}$ & $\mathrm{~L}_{\mathrm{h} 5}$ & $\mathrm{~W}_{\mathrm{h} 6}$ & $\mathrm{~L}_{\mathrm{h} 6}$ & \\
13.3 & 8.4 & 1.4 & 0.7 & 6.65 & \\
\hline
\end{tabular}

\section{Results and Discussion}

The proposed antenna's performance in terms of $S_{11}$ and gain spectra is evaluated using the CST MWS software package [20]. Numerically, the proposed antenna design is parametrically studied to arrive at the optimal antenna design. Therefore, the fractal order is varied from $0^{\text {th }}$, solid rectangular traditional patch, to a fractal patch based on the $3^{\text {rd }}$ order. As seen in Fig. 2, it is found that when increasing the number of iterations, resonance frequencies increased and shifted by scale ratio to the low frequency. therefore, the proposed antenna reduces the size of the antenna by about $75 \%$.

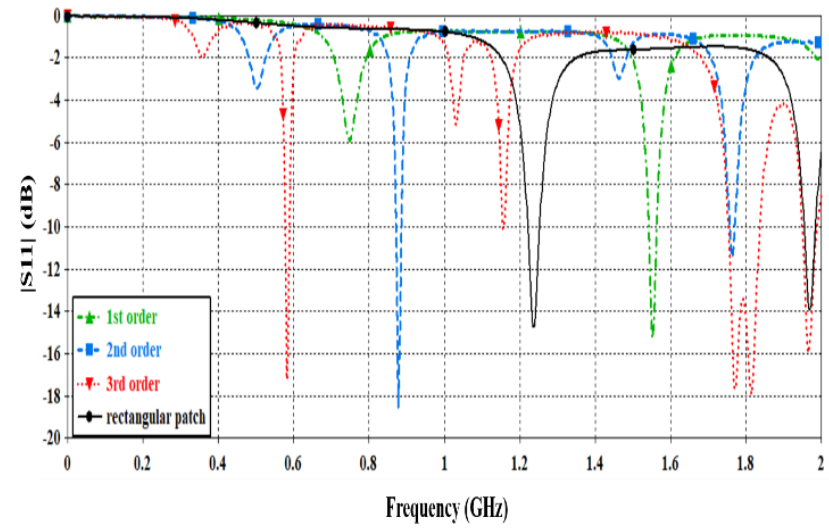

Figure 2. Antenna $S_{11}$ spectra based on a parametric study by changing the fractal order.
Now, to ensure the required bandwidth and gain enhancement, the authors modified the geometry of the ground plane by etching a rectangular aperture underneath the patch area only as illustrated in Fig. 1. (b) Such aperture is etched to avoid the capacitive coupling effect between the patch edges and the fractal slots by the ground plane metallization which reduces the antenna gain and radiation efficiency [21].

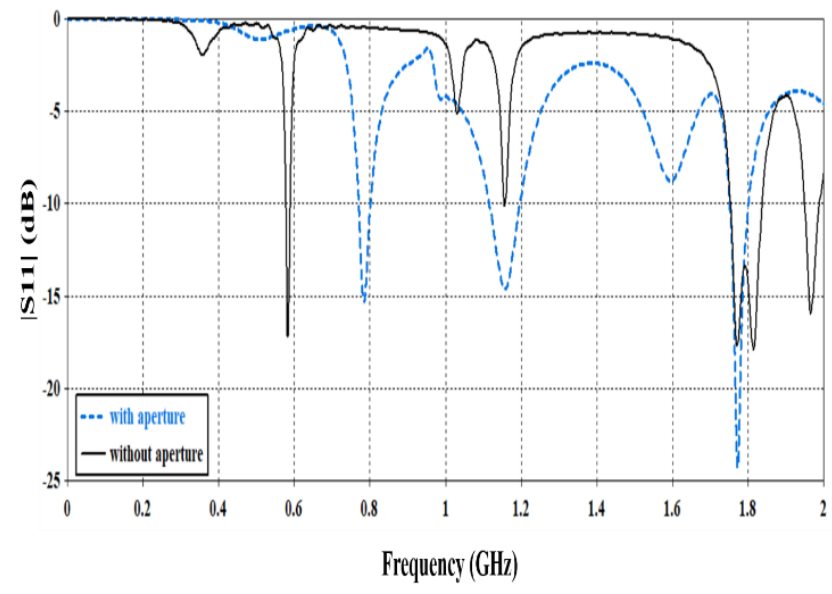

(a)

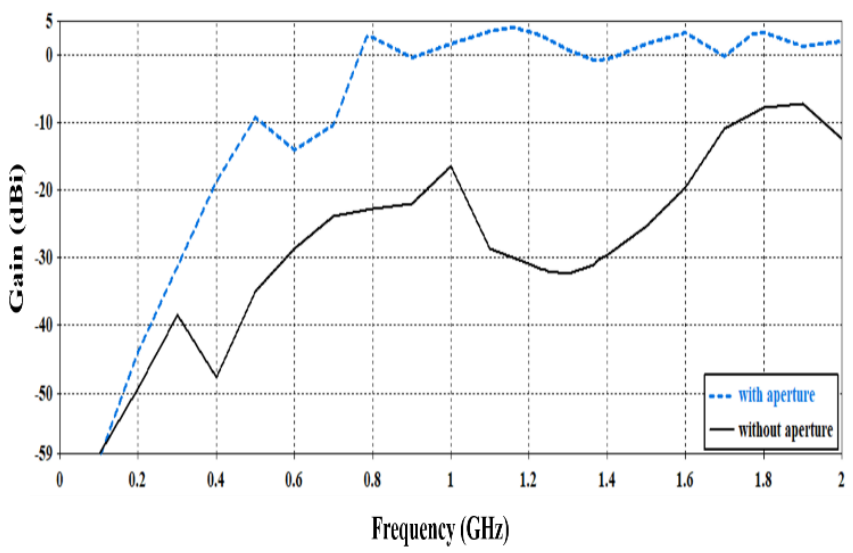

(b)

Figure 3. Comparison between the antenna performance with and without ground plane aperture: (a) $S_{11}$ and (b) gain spectra.

Fig. 3 illustrates a comparison in terms of $S_{11}$ Fig. 3 (a) and gain spectra Fig. 3 (b) respectively when the antenna has an aperture and without it. We noticed introducing the ground plane 
aperture improves antenna bandwidth-gain product significantly. It can be seen from fig. 3(a) at the frequency resonance $\mathrm{f} 1=0.784 \mathrm{GHz}$, the return loss of antenna is about $-15.325 \mathrm{~dB}$, whereas at $\mathrm{f} 2=1.158 \mathrm{GHz}$ return loss is about 14.628, and at $\mathrm{f} 3=1.772 \mathrm{GHz}$ is about -24.259 dB. Fig. 4 and 5 show the 2D \& 3D simulation of far-field radiation patterns for the suggested antenna at all frequencies of resonance. It is found that at the resonant frequencies $\mathrm{f} 1, \mathrm{f} 2$, and f3 the proposed antenna achieves a gain of about $2.7 \mathrm{dBi}, 3.92 \mathrm{dBi}$, and $3.02 \mathrm{dBi}$ respectively.

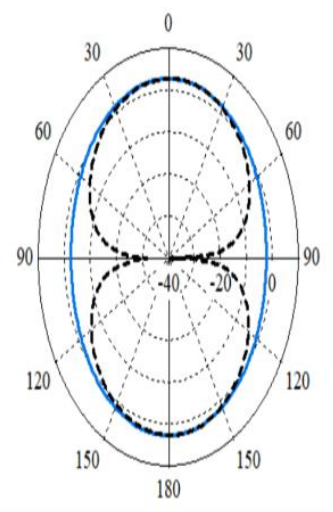

$\mathrm{F}=0.784 \mathrm{GHz}$

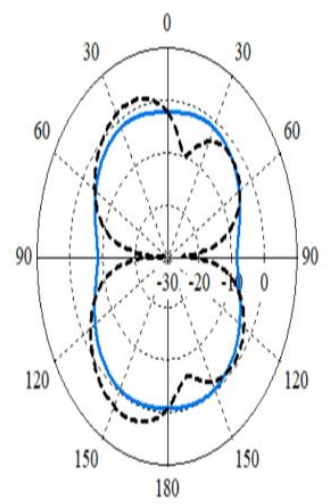

$\mathbf{F}=1.772 \mathrm{GHz}$

Figure 4. the Simulation of 2D radiation pattern at different frequencies.

$\mathrm{F}=1.158 \mathrm{GHz}$
- E- Plane

-.-.-H - Plane

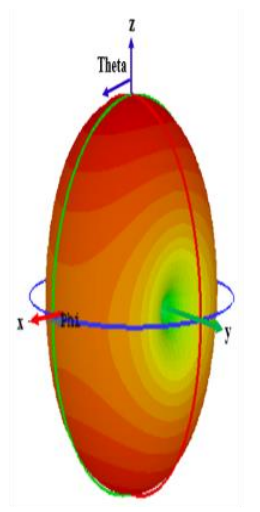

$\mathrm{F}=0.784 \mathrm{GHz}$

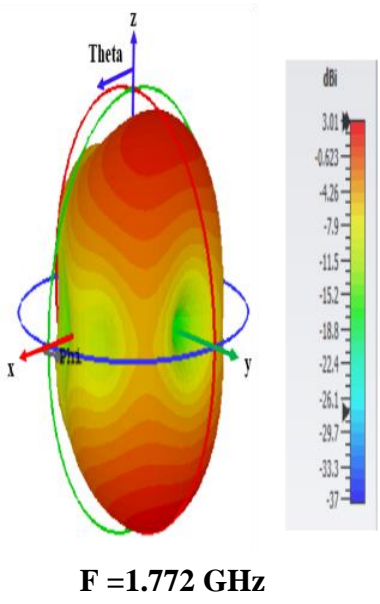

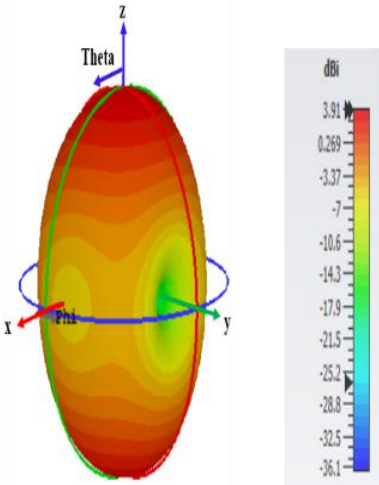

$\mathrm{F}=1.158 \mathrm{GHz}$

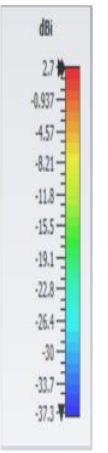

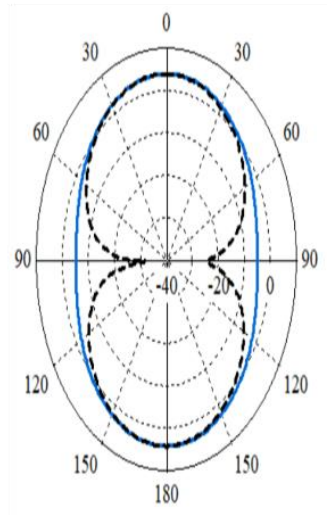

Figure 5. the Simulation of 3D radiation pattern at different frequencies.

Radiation patterns of the proposed antenna take up the upper hemispheric shape that required and useful for GSM uses [16]. A deeper understanding of the suggested antenna can be getting by the monitoring distribution current on the surface of the antenna, which was presented at all resonance frequencies as illustrated in Fig. 6 . we can be observed that the antenna structure's maximum surface current values are located at specific locations according to the resonance frequency. 


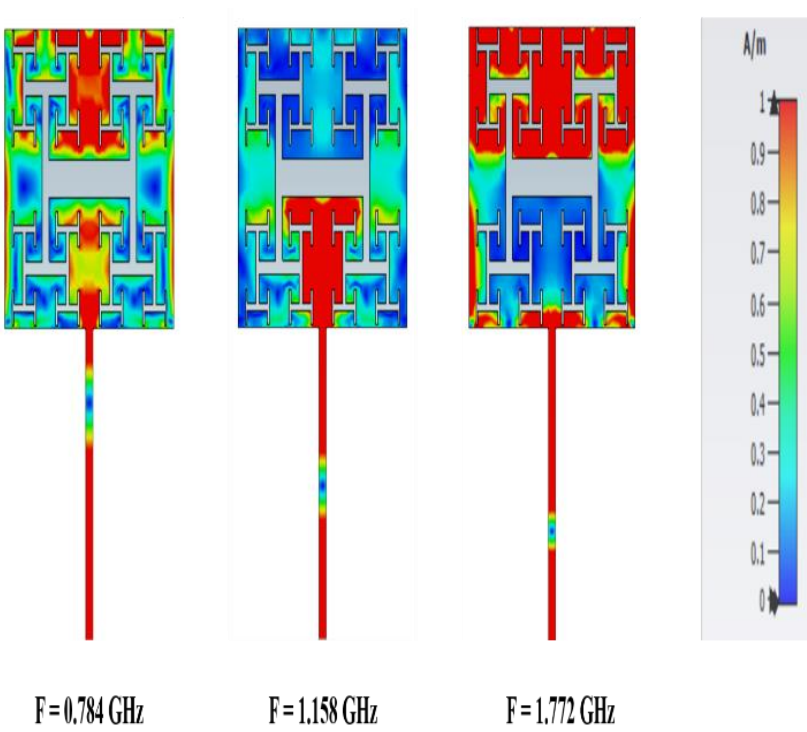

Figure 6. Surface current distribution on the patch of modeled antenna.

Based on that, it can be seen from the results in Fig. 6, the main concentration of the current is found to be at the upper part of the patch at the middle $\mathrm{H}$ - slot to show a resonance at $0.784 \mathrm{GHz}$. However, at $1.158 \mathrm{GHz}$, the current is mostly concentrated at the lower side of the patch. Finally, it is found that the most current concentrated at the upper side of the patch including the middle and side of H-slots. A comparison of our proposed work with other antennas in the same region in terms of resonance frequency, S11, gain, and application is covered to evaluate the performance of the proposed design is shown in Table 2.

Table 2. Performance comparison of H-tree fractal

\begin{tabular}{cccc}
\multicolumn{4}{c}{ antenna } \\
\hline Ref. & Fr $(\mathbf{G H z}) /$ S11 $(\mathbf{d B})$ & $\begin{array}{c}\text { Gain } \\
(\mathbf{d B i})\end{array}$ & $\begin{array}{c}\text { Application } \\
\text { Covered }\end{array}$ \\
\hline$[22]$ & $1.95 /-14.5$ & 1.5 & \\
& $3.3 /-17$ & 2.1 & WLAN, \\
& $3.6 /-24$ & 2 & WiMAX \\
& $5.8 /-17$ & 5 &
\end{tabular}

[19]

$\begin{array}{llc}1.72 /-40.63 & 1.9 & \\ 2.30 /-22.66 & 2.4 & \text { LTE, PCS, } \\ 3.30 /-14.91 & 3.8 & \text { WIMAX, } \\ 3.65 /-19.51 & 3.1 & \text { WLAN }\end{array}$

[23]

$\begin{array}{ccc}3.6 /-21.5 & 0.3 & \text { WLAN, } \\ 4.75 /-11.5 & 0.3 & \text { WIMAX, } \\ 5.74 /-22.3 & 2.8 & \text { RIFD } \\ 6.71 /-28.4 & -- & \text { HiperLAN } \\ 8.57 /-21 & 0.8 & \end{array}$

This

$0.784 /-15.325$

2.7

work

$1.158 /-14.628$

3.92

GSM

\section{Conclusion}

The suggested antenna design is performed to the applications of modern wireless communication systems within the frequency bands around 0.784 $\mathrm{GHz}, 1.158 \mathrm{GHz}$, and $1.772 \mathrm{GHz}$. The antenna radiation patterns at the frequency bands of interest are evaluated numerically and validated as well. We found that the suggested antenna shows excellent matching with a significant gain enhancement around the frequency band of interest. The suggested antenna is found to be an excellent candidate for many modern wireless communication systems including the GSM network.

\section{Acknowledgments}

The authors wish to thank Al-Mustansiryah University for supporting this research.

\section{Conflict of interest}

The authors declare that this research does not conflict with any other work. 


\section{References}

1. Mandelbrot, B. B. (1984). "The Fractal Geometry of Nature". New York, W. H. Freeman, vol. 91, pp. 594-598,

2. Zhang, Y. Wu, C.Y. (2016). "An approach for optimizing the reconfigurable antenna and improving its reconfigurability". IEEE International Conference on Signal Processing, Communications and Computing,

3. Jaggard, D. L. (1990). On Fractal Electrodynamics. Springer Verlag, "Recent Advances in Electromagnetic Theory”. New York, pp. 183-224,

4. Awad, A. Chahine, S. A. Osman, Z. Kabalan, K. Y. (2008). "Investigation of Htree Multiband Prefractal Antennas". IMETI International Multi-Conference on Engineering and Technological Innovation,

5. Tumakov, D. Chikrin, D. Kokunin, P. (2020). "Miniaturization of a Koch-Type Fractal Antenna for Wi-Fi Applications". Mdpi Fractal and Fractional, vol. 4,

6. Alrayes, N. Hussein, M. I. (2021). "Metamaterial-based sensor design using split ring resonator and Hilbert fractal for biomedical application”. Elsevier Sensing and Bio-sensing, vol. 31.

7. Elwi, T. A. Hassain, Z. A. A. Tawfeeq, O. A. (2019). "Hilbert metamaterial printed antenna based on organic substrates for energy harvesting". IET Microwaves, Antennas \& Propagation, vol. 13, pp. 2185-2192,

8. Obaid, S. M. Elwi, T. A. Ilyas, M. (2021). "Fractal Minkowski-Shaped Resonator for Noninvasive Biomedical Measurements: Blood Glucose Test". PEIR C Progress in Electromagnetics Research C, vol. 107, pp. 143-156,

9. Chowdary, P. S. R. Prasad, A. M. Rao, P. M. Anguera, J. (2015). "Design and performance study of Sierpinski fractal based patch antennas for multiband and miniaturization characteristics". Springer wireless personal communications, vol. 83, pp. 1713-1730,

10. Hassain, Z. A. A. (2014). "Design of UltraWideband Microstrip Antennas with Slots and Fractal Based Ground Plane". AlRafidain University College for Sciences,

11. Wang, Y. Guan, J. Geng, Y. Feng, C. (2020). "A miniaturised LS Peano fractal antenna for partial discharge detection in gas insulated switchgear". Sensors \& Transducers, vol. 240, pp. 19-25,

12. Cao, X. Luo, B. Zhu, Y. Xia, Z. Cai, Q. (2020). "Research on the defected ground structure with von Koch snowflake fractals". IEEE Access, vol. 8, pp. 3240432411,

13. Sohi, A. K. Kaur, A. (2020). "A complementary Sierpinski gasket fractal antenna array integrated with a complementary Archimedean defected ground structure for portable 4G/5G UWB MIMO communication devices". Wiley Online Library Microwave and Optical Technology Letters, Vol. 62, pp. 25952605,

14. Ali, J. K. Hassain, Z. A. A. Osman, A. A. Salim, A. J. (2012). "A new compact size fractal based microstrip slot antenna for GPS applications". PIERS Proceedings,

15. Gurjar, R. Upadhyay, D. K. Kanaujia, B. K. Kumar, A. (2020). "A compact modified Sierpinski carpet fractal UWB MIMO antenna with square-shaped funnel-like ground stub". Elsevier AEU- International Journal of Electronics and Communications. Vol. 117,

16. Hassain, Z. A. A. Sahrab, A. A. Osman, . A. Jwad, A. (2018)." New Design of TriBand, Small Size Microstrip Slot Antenna Based on Fractal Geometry for Mobile and Wireless Communications”. IEEE 
Mediterranean Microwave Symposium (MMS),

17. Haran, M. Kumar, G. D. Garvin, A. F. Ramesh, S. (2020). "Hexagonal microstrip patch antenna for early-stage skin cancer identification".begellhouse

Telecommunications and Radio Engineering vol. 79,

18. Fadamiro, A. O. Famoriji, O. J. Zakariyya, R. S. Zhang, Z. Lin, F. (2019). "Design of H-Tree fractal slots frequency reconfigurable hexagonal patch antenna using PIN diodes". Journal of Electromagnetic Waves and Applications. Vol. 33, pp. 1591-1604,

19. Tarbouch, M. El Amri, A. Terchoune, H. Barrou, O. (2018). "A compact microstrip patch antenna based on fractal geometry on the ground plane". IEEE International Conference on Advanced Communication Technologies and Networking (CommNet), pp. 1-8,

20. CST Microwave Studio. [Online]. Available: http://www.cst.com.

21. Mark, R. Mishra, N. Mandal, K. Sarkar, P. P. Das, S. (2018). "Hexagonal ring fractal antenna with dumb bell-shaped defected ground structure for multiband wireless applications". Elsevier AEU-International Journal of Electronics and Communications. Vol. 94, pp. 42-50.

22. Reha, A. El Amri, A. (2016) "Design, Realization and Measurements of CPWFed Microstrip Hexagonal Patch Antenna with H-Tree Fractal Slots for WLAN and WIMAX Applications". Int. J. Microw. Opt. Technol. Vol. 11, pp 251-258.

23. Reha, A. El Amri, A. Benhamammouch, O. Said, A. O. (2016). "CPW-fed H-tree fractal antenna for WLAN, WIMAX, RFID, C-band, HiperLAN, and UWB applications". International Journal of
Microwave and Wireless Technologies. Vol. 8, pp. $327-334$. 